\section{Deep brain stimulation in Tourette syndrome: the known and the unknown}

\author{
Kirsten R Muller-Vahl ${ }^{\circ}$
}

\section{How much data are needed to conclude the effectiveness of deep brain stimulation in Tourette syndrome?}

The paper by Johnson et $a l^{1}$ is based on a collaboration with the International Tourette Syndrome (TS) Deep Brain Stimulation (DBS) database and registry. This TS DBS database/registry has been initiated in 2012 by a group of researchers and clinicians led by Michael Okun. They aimed to collect as many data as possible to increase the database on efficacy, safety and surgical approaches of DBS in TS. Without any doubt, there is a critical need to increase current knowledge since the absolute number of patients who received DBS is still low and until today only a very limited number of randomised controlled trials (RCTs) including only a small number of patients have been performed. Twenty years after the introduction of DBS in the treatment of TS, less than 200 patients have been reported in the literature and data of only five RCTs have been published including 3 to 16 patients (altogether $\mathrm{N}=43$ patients). Furthermore and in contrast to most other indications, in TS the optimal target is still unknown. So far, 10 different brain areas have been suggested including four targets in the centromedial (CM) thalamus, the anteromedial and the posteroventrolateral part of the globus pallidus internus (GPi), the globus pallidus externus, the nucleus accumbens, the anterior limb of internal capsule and the subthalamic nucleus.

This is the first study that aimed to identify the optimal target for DBS in patients with TS including a large sample $(\mathrm{N}=110$ patients from 13 different institutions across three different continents) by using the DBS TS database/registry. In line with recent results based on this database/registry ${ }^{2}$ and a meta-analysis, ${ }^{3}$ the authors found a significant improvement of tics and obsessive-compulsive behaviour after DBS $(\mathrm{p}<0.01)$. Remarkably, best improvement in tics (40\%) was reached only 13 months after surgery.

Department of Psychiatry, Socialpsychiatry and Psychotherapy, Hannover Medical School, Hannover, Germany

Correspondence to Dr Kirsten R Muller-Vahl, Department of Psychiatry, Socialpsychiatry and Psychotherapy, Hannover Medical School, Hannover 30623, Germany; mueller-vahl.kirsten@mh-hannover.de
However, the authors failed to identify any significant differences across different targets. The most often used targets (GPi and CM thalamus) were effective in some patients, but ineffective for others.

This important work sheds further light on the value of DBS in TS, but in parallel raises several important questions. While the utilisation of the TS DBS database/registry is a major advantage, at the same time it is the most significant limitation of this study: the registry aims to combine outcome information from a variety of centres worldwide without restrictions on investigators or groups who wish to join the project. In addition, there is no limitation to the maximum data necessary to register a case. Although researchers were encouraged to submit positive as well as negative results, it can be assumed that there is a relevant reporting bias towards more positive experiences. Finally, the majority of data are based on case reports and open uncontrolled studies, but not on RCTs. This is of utmost importance since the largest $\mathrm{RCT}^{4}$ failed to demonstrate a significant improvement of tics at the end of the 3-month double-blind period, but tics were decreased after the following 6-month open-label period. In line with the data reported in this issue by Johnson et al, ${ }^{1}$ the authors ${ }^{4}$ argued that in TS the time to respond to DBS is on the order of multiple months and optimal parameter settings are needed. However, alternatively one may speculate that open uncontrolled data are influenced by several other factors including spontaneous fluctuations, environmental and psychosocial factors, but also the presence of functional 'tic-like' movements as suggested recently. ${ }^{5}$

Similarly, the fact that the authors failed to identify differences between different targets can be interpreted in two different ways: it can be speculated that in TS it is important to modulate an abnormal cortico-striato-thalamo-cortical network instead of stimulating a single circumscriptive brain area to restore abnormal function; but alternatively, it can also be argued that TS DBS is not superior to sham stimulation-as suggested by some of the small RCTs-and therefore stimulation of several different brain areas results in comparable clinical effects.

Although the authors were able to use a unique sample for their analyses and results based on such databases are urgently needed, when interpreting the results it must be taken into consideration that these results can only be as good as the underlying database. Unfortunately, in TS, the database is still very weak and therefore final conclusions on the efficacy of DBS cannot be drawn. Remarkably, even several years after the introduction of DBS in the treatment of TS, even severely affected patients are still very cautious to decide for DBS.

\section{Contributors The editorial is written by myself.}

Funding The authors have not declared a specific grant for this research from any funding agency in the public, commercial or not-for-profit sectors.

Competing interests KRM-V has non-financial competing interests as a member of the medical advisory board of the Tourette Association America (TAA), the scientific advisory board of the German Tourette Association (TGD), the board of directors of the German (ACM) and the International (IACM) Association for Cannabinoid Medicines, and the committee of experts for narcotic drugs at the federal opium bureau of the Federal Institute for Drugs and Medical Devices (BfArM) in Germany; has received financial or material research support from the EU (FP7HEALTH-2011 no. 278367, FP7-PEOPLE-2012-ITN no. 316978), the German Research Foundation (DFG: GZ MU 1527/3-1), the German Ministry of Education and Research (BMBF: 01KG1421), the National Institute of Mental Health (NIMH), the Tourette Gesellschaft Deutschland e.V., the Else-Kroner-Fresenius-Stiftung, and GW, Almirall, Abide Therapeutics, and Therapix Biosiences; has served as a guest editor for Frontiers in Neurology on the research topic "The neurobiology and genetics of Gilles de la Tourette syndrome: new avenues through large-scale collaborative projects", is an associate editor for Cannabis and Cannabinoid Research and an Editorial Board Member of Medical Cannabis and Cannabinoids; has received consultant's honoraria from Abide Therapeutics, Tilray, Resalo Vertrieb $\mathrm{GmbH}$ and Wayland Group, speaker's fees from Tilray, and royalties from Medizinisch Wissenschaftliche Verlagsgesellschaft Berlin, Elsevier and Kohlhammer; and is a consultant for Nuvelution TS Pharma Inc., Zynerba Pharmaceuticals, Resalo Vertrieb $\mathrm{GmbH}$, CannaXan GmbH, Therapix Biosiences and Columbia Care.

Patient consent for publication Not required.

Provenance and peer review Commissioned; internally peer reviewed.

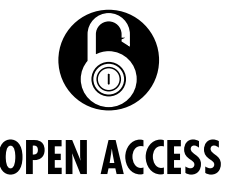

Open access This is an open access article distributed in accordance with the Creative Commons Attribution Non Commercial (CC BY-NC 4.0) license, which permits others to distribute, remix, adapt, build upon this work non-commercially, and license their derivative works on 
different terms, provided the original work is properly cited, appropriate credit is given, any changes made indicated, and the use is non-commercial. See: http:// creativecommons.org/licenses/by-nc/4.0/.

(c) Author(s) (or their employer(s)) 2019. Re-use permitted under CC BY-NC. No commercial re-use. See rights and permissions. Published by BMJ.

\section{Check for updates}

To cite Muller-Vahl KR. J Neurol Neurosurg Psychiatry 2019;90:1076-1077.

Received 13 June 2019

Accepted 14 June 2019
Published Online First 12 July 2019

\section{Linked}

http://dx.doi.org/10.1136/jnnp-2019-320379

J Neurol Neurosurg Psychiatry 2019;90:1076-1077. doi:10.1136/jnnp-2019-321008

\section{REFERENCES}

1 Johnson KA, Fletcher PT, Servello D, et al. Image-Based analysis and long-term clinical outcomes of deep brain stimulation for Tourette syndrome: a multisite study. J Neurol Neurosurg Psychiatry 2019;90:1078-90.
2. Martinez-Ramirez D, Jimenez-Shahed J, Leckman JF, et al. Efficacy and safety of deep brain stimulation in Tourette syndrome: the International Tourette Syndrome Deep Brain Stimulation public database and registry. JAMA Neurol 2018;75:353-9.

3. Baldermann JC, Schüller T, Huys D, et al. Deep brain stimulation for Tourette-syndrome: a systematic review and meta-analysis. Brain Stimul 2016:9:296-304.

4. Welter M-L, Houeto J-L, Thobois S, et al. Anterior pallidal deep brain stimulation for Tourette's syndrome: a randomised, double-blind, controlled trial. Lancet Neurol 2017:16:610-9.

5. Müller-Vahl K, Szejko N, Luetjens G, et al. Randomized double-blind controlled trial of thalamic versus GPI stimulation in patients with Gilles de la Tourette syndrome. F1000 Research 2019. 